\title{
CONTROLE BIOLÓGICO DA MURCHA BACTERIANA DO TOMATEIRO, POR Pseudomonas spp. FLUORESCENTES ${ }^{1}$
}

\author{
BIOLOGICAL CONTROL OF BACTERIAL WILT OF TOMATO \\ BY FLUORESCENT Pseudomonas spp
}

Ana Rosa Peixoto ${ }^{2}$

- REVISÃO BIBLIOGRÁFICA -

Esta revisão bibliográfica teve como objetivo avaliar o potencial de antagonismo de espécies de Pseudomonas fluorescentes a Pseudomonas solanacearum, agente causal da murcha bacteriana do tomateiro. Devido a dificuldade encontrada nas estratégias utilizadas para o controle da Murcha Bacteriana por meio de métodos convencionais, alguns outros tem sido estudados, como o uso de microrganismos benéficos. As rizobactérias vem proporcionando solução viável a algumas doenças consideradas de difícil manejo. Dentre os mecanismos que tem sido sugeridos para o controle microbiano de patógenos de plantas, através do uso de rizobactérias fluorescentes, citamse produção de antibióticos, bactericinas, enzimas titicas, competição por espaço e nutrientes. Possuem uma alta capacidade de colonização e sobrevivência no hospedeiro, falares que são importantes no estabelecimento e introdução de microrganismos na rizosfera. Estas bactérias podem também incitar um aumento no desenvolvimento e na produção do hospedeiro, sendo denominadas de rizobactérias promotoras de crescimento de plantas.

Palavras-chave: antagonismo, rizobactéria, Pseudomonas solanacearum
SUMMARY

This literature review has the objetive of evaluating the antagonism potential ofspecies of florescem pseudomonas to Pseudomonas solanacearum which is the causal agent of bacterial wilt on the tomato crop. Due to serious limitation in the eificiency of conventional methods of contrai, other strategies have been siudied, such as the use o/beneficiai microrganisms. Rhizobacteria have shown to be a viable alternative in the contrai of some diseases of difficult managmenl. Among the mechanisms which have been suggestedfor microbian control ofplantpathogens with fluorescent rhizobacteria, can be used antibiotic production, bacteriocin, uric emimes and competition for colonization and survival capacity on the host. The survival capacity is very important in the introduction and stablishment ofthe microrganisms in the rhizosphere. These bacteria can aiso increse the development andyield of the host and can be calledplant growth promete rhizobacteria.

Key words: antagonism, rhizobacteria, Pseudomonas solanacearum

\footnotetext{
${ }^{1}$ Parte da Dissertação de Mestrado apresentada pela autora à UFRPE, Recife - PE, em Maio de 1994.

${ }^{2}$ Engenheiro Agrônomo, Mestre em Fitossanidade, Bolsista DCR-CNPq/EMBRAPA-CPATSA, Cx. Postal 23, 56300-000, Petrolina PE. Autor para correspondência.
} 


\section{INTRODUÇÃO}

No Brasil, o tomateiro (Lycopersicon esculentum, Mill) situa-se entre as hortaliças mais cultivadas, sendo produzida na maioria dos Estados, no entanto, está sujeita a uma gama considerável de patógenos, sendo as bactérias responsáveis por grandes prejuízos. Segundo MALA VOLTA JR. \& RODRIGUES NETO (1991), as fitobactérias chegam a ser fator limitante à exploração económica desta solanácea.

Entre as bacterioses do tomateiro, a murcha bacteriana causada por Pseudomonas solanaceraum (Smith) Smith é uma das mais importantes, nas regiões tropicais e subtropicais do globo (BUDDENHAGEN \& KELMAN, 1964), incidindo sobre solanáceas, em geral, sempre com alta severidade. $\boldsymbol{P}$. solanacearum é um patógeno de difícil controle, pois, além da grande variabilidade fisiológica e largo círculo de hospedeiros, esta bactéria sobrevive infectando hospedeiros alternativos, como saprófito na rizosfera de diversas ervas daninhas ou no solo, propriamente dito, desde que exista alta umidade (GRANADA \& SEQUEIRA, 1983).

Segundo ROBES (1991), o biocontrole pela introdução ou pelo manejo de bactérias antagónicas nos locais de colonização do patógeno, é um processo económico e compatível com as comunidades agrícolas de baixa renda, não causando impactos no ambiente, nem efeitos tóxicos. Dentre as bactérias antagónicas que vêm demostrando boa colonização no rizoplano ou sobrevivendo em saprogênese na rizosfera, as Pseudomonas do grupo fluorescente apresentam-se com alto potencial para o controle biológico.

Nesta revisão bibliográfica são enumerados os trabalhos que evidenciam o potencial antagónico de espécies de pseudomonas fluorescentes em relação a $\boldsymbol{P}$. solanacearum, bem como a capacidade de colonização, sobrevivência e a habilidade que possuem de incitar o aumento no desenvolvimento e na produção de plantas.

\section{CONSIDERAÇÕES GERAIS SOBRE A DOENÇAS E O PATÓGENO}

No Brasil, a Murcha Bacteriana ocorre em todas as regiões (REIFSCHNEIDER \& TAKATSU, 1985), tomando-se fator limitante para o cultivo de solanáceas, inclusive na zona da Mata do Estado de Pernambuco (MARIANO et al., 1989).

$\mathrm{O}$ agente causal que foi pela primeira vez relatado no Brasil, por McCORMACK (1937) como
Bacterium solanacaerum (Smith) Chester, pode infectar mais de 200 espécies de plantas, pertencentes a 33 diferentes famílias botânicas, com um grande número de hospedeiras entre as solanáceas (SINHA, 1986).

Pseudomonas solanacearum sobrevive no solo por longos períodos e penetra na planta através de ferimentos das raízes, que podem ser causados por nematóides, transplantio de mudas (BUDDENHAGEM \& KELMAN, 1964), implementos agícolas, bem como, pelo desbaste de plantas. É de ocorrência mais comum em solos pesados, úmidos e em temperatura altas (SINHA, 1986). Há relatos da transmissão do patógeno, a partir de sementes contaminadas, para cotilédones e folhas de tomateiro bem como plantas de pimentão (Capsicum spp.) (MOFFET et al., 1981) indicando, portanto, que sementes infectadas podem ser um importante meio de dispersão natural deste organismo.

Uma vez estabelecida no hospedeiro, a bactéria multiplica-se rapidamente nos tecidos do xilema, formando uma substância viscosa abundante (KELMAN, 1954). Há produção de enzimas celulíticas e pectinolíticas, causando desorganização do tecido vascular, podendo, indiretamente, impedir o movimento de água e nutrientes, resultando em perdas de turgercência (WALLIS \& TRUTER, 1978).

Os sintomas externos iniciais caracterizam-se por murcha de folíolos e epinastia foliar. Com a evolução da doença, esse quadro de murcha afeta toda a planta e toma-se irreversível causando a morte. Como a infecção é sistémica, o corte da haste próximo do solo mostra o sistema vascular escurecido e, a compressão do caule origina exsudato bacteriano (MALA VOLTA JR. \& RODRIGUES NETO, 1991).

De acordo com PERSLEY et al. (1986) existem cinco raças de $\boldsymbol{P}$. solanacearum, diferindo quanto aos hospedeiros, distribuição geográfica e habilidade de sobreviver sob diferentes condições de ambiente. A raça 1 é patogênica a um amplo número de hospedeiras, incluindo fumo (Nicotina tabacum, L.), tomateiro e certas bananeiras diplóides (Musa, grupos $\mathrm{BB}$ ou $\mathrm{AA}$ ), em regiões tropicais $\mathrm{e}$ subtropicais. A raça 2 infecta $\mathbf{M u s a}$, grupos AAA, $\mathrm{AAB}$ e $\mathrm{ABB}$, Heliconia spp. e alguns hospedeiros perenes, estando inicialmente limitada aos trópicos americanos, achando-se agora difundida pela Ásia. A raça 3 é patogênica a batata (Solanum tuberosum. L.) e poucas hospedeiras como o tomate, sendo encontrada nas regiões tropicais e subtropicais. A raça 4, que é patogênica ao gengibre (Zingiber qfficinale, Roscoe), foi detectada nas Filipinas e a raça 5, que infecta a amoreira (Morus alba. L.), é difundida na China. 
Estudando a variabilidade de $\boldsymbol{P}$. solanacearum quanto a capacidade de utilizar e produzir ácido a partir de açucares (maltose, lactose e celobiose) e de álcoois (manitol, sorbitol e ducitol), HAYWARD (1964) classificou-a em quatro biovares. $\mathrm{O}$ biovar I não utiliza e não produz ácido a partir dos açucares e dos álcoois; a II utiliza e produz ácido apenas a partir dos açucares; a III utiliza e produz ácido a partir dos açucares e dos álcoois; a IV utiliza e produz ácido a partir dos álcoois. Levantamentos conduzidos nas diversas regiões brasileiras indicam a existência do biovar I em todas regiões, enquanto a biovar II predominam em climas amenos e o biovar III no Norte e Nordeste (REIFSCHNEIDER \& TAKATSU, 1985).

\section{Estratégias de controle da Murcha Bacteriana}

O controle da Murcha Bacteriana é difícil devido ao grande círculo de hospedeiras do patógeno, à complexidade que envolve a sobrevivência da bactéria no solo (KELMAN, 1976) e alta variabilidade genética (MARTINS et al., 1988).

O controle da Murcha Bacteriana deve ser integrado, utilizando-se, principalmente, variedades resistentes (RAO et al., 1975). Embora algumas cultivares de tomateiros resistentes à murcha tenham sido desenvolvidas com sucesso, é comprovadamente difícil a obtenção e adaptação das mesmas sob condições de altas temperaturas e umidade (MEW \& HO, 1976). Este método de controle é também dificultado devido a grande variabilidade genética da bactéria e pela introdução de material contaminado em áreas isentas da doença (REIFSCHNEIDER \& TAKATSU, 1985).

A rotação de cultura é uma prática recomendada no controle da Murcha Bacteriana. No entanto, a habilidade de estirpes de $\boldsymbol{P}$. solanacearum causarem infecção latente nas raízes de hospedeiros alternativos ou plantas presumivelmente não hospedeiras sem exprimirem sintomas, permite a multiplicação da bactéria e manutenção de um alto nível de inoculo no solo. Isto garante a sobrevivência do patógeno e toma difícil o controle da doença através da rotação (HAYWARD, 1986).

Devido a dificuldade encontrada nas estratégias utilizadas para controle da Murcha Bacteriana do tomateiro, alguns outros métodos têm sido estudados, tais como, o controle biológico pelo uso de microrganismos benéficos, que vem proporcionando solução viável para algumas doenças consideradas de difícil manejo (SIMON $\boldsymbol{e t}$ al., 1990).

Conforme WELLER (1988), as bactérias associadas à rizosfera/rizoplano, incluindo aquelas utilizadas em controle biológico, são designadas comumente por rizobactérias. Para o controle da Murcha Bacteriana, os agentes biologicamente utilizados incluem rizobactérias antagónicas (CIAMPI-PANNO et al., 1989) e mutantes avirulentos de $\boldsymbol{P}$. solanacearum (McLAUGHLIN \& SEQUEIRA, 1988). Os mecanismos de antagonismo envolvidos podem ser: resistência induzida, colonização ativa da rizosfera do solo, produção de bacteriocinas, utilização de bacteriófagos (WALL \& SANCHEZ, 1993), e, ainda, proteção por competição (McLAUGHLIN \& SEQUEIRA, 1988).

\section{Controle biológico da Murcha Bacteriana}

Vários resultados têm sido obtidos com êxitos parciais ou totais no biocontrole da Murcha Bacteriana do tomateiro. O isolado PP22 de $\boldsymbol{P}$. putida inibiu o crescimento de um largo espectro de bactérias fitopatogênicas em meio de cultura, dentre os quais um isolado de P. solanacearum (LIÃO, 1989). De 125 isolados de espécies de pseudomonas fluorescentes e 52 não fluorescentes testados em laboratório para antagonismo a $\boldsymbol{P}$. solanacearum, $\boldsymbol{P}$. fluorescens (Pfcp) e Bacilius spp. (B33 e B36) protegeram plântulas de banana, beringela e tomate, respectivamente, com valores de 50,61 e 91\%, em casa-de-vegetação e 50,49 e 36\%, em campo. Esses isolados também promoveram o aumento no peso e biomassa dessas plantas (ANURATHA \& GNAMANICKAM, 1990).

MARIANO et al. (1989) visando a obtenção de biocontroladores para uso num programa de controle integrado da Murcha Bacteriana das solanáceas, os isolados P2 e SDR2 de $\boldsymbol{P}$. fluorescens e C21 de $\boldsymbol{P}$. marginalis foram aplicados a plantas de tomate com 21 dias de idade cultivadas em solo natural e esterilizado dois dias antes, simultaneamente e dois dias após à inoculação com $\boldsymbol{P}$. solanacearum. $O$ isolado $\mathrm{P} 2$ foi indicado como melhor antagonista, embora reduzindo a severidade da doença em apenas 20,3\%. A aplicação simultânea revelou-se como melhor método de aplicação do antagonista. Um maior controle foi observado em solo natural, sugerindo uma interação positiva entre os antagonistas utilizados e a microflora original do solo.

Segundo HARTMAN et al (1993), $\boldsymbol{P}$. cepacia, $\boldsymbol{P}$. fluorescens $\boldsymbol{e} \boldsymbol{P}$. gladioli inibiram o crescimento de $\boldsymbol{P}$. solanacearum em meio de cultura. Suspensões de $\boldsymbol{P}$. cepacia aplicadas ,no solo, sete dias antes da inoculação com o patógeno, resultaram em $65 \%$ da redução da Murcha Bacteriana do tomateiro quando comparados com os tratamentos testemunha. Em condições de casa-de-vegetação, uma combinação

Ciência Rural, v. 27n. 11997 
de $\boldsymbol{P}$. fluorescens e Terlai, bactericida experimental, foi testada para o controle desta doença. Terlai controlou efetivamente a Murcha Bacteriana, especialmente quando aplicado antes da inoculação com $\boldsymbol{P}$. solanacearum, sugerindo-se uma aplicação de $\boldsymbol{P}$. fluorescens e então uma segunda aplicação do bactericida.

Em experimento conduzido por RIBEIRO \& TAKATSU (1993), rizobactérias isoladas de plantas invasoras foram selecionadas in vitro, quanto à inibição do crescimento de $\boldsymbol{P}$. solanacearum e, em seguida, testados em casa de vegetação, quanto ao controle da Murcha Bacteriana do tomateiro. Plantas invasoras foram inoculadas com estas rizobactérias e cultivadas em solo infestado com o patógeno por 90 dias. Após este período, fez-se o corte das invasoras rente ao solo e cultivaram-se tomateiros. Os resultados mostraram que não houve controle efetivo da doença, mas alguns isolados reduziram e ou retardaram os sintomas até 20 dias.

\section{MECANISMOS DE AÇÃO DE Pseudomonas spp. FLUORESCENTES}

As pseudomonas fluorescentes benéficas e outros microrganismos podem promover o crescimento de plantas e induzir supressividade de doenças (HOWEL \& STIPANOVIC, 1979). Dentre os mecanismos que têm sido sugeridos para o controle microbiano de patógenos de plantas, citamse produção de antibióticos, bacteriocinas, enzimas líticas, bem como, competição por espaço e nutrientes (HORNY, 1979; KLOEPPER e/aí, 1980).

Sideróforos são compostos de baixo peso molecular, que quelatizam o ferro e funcionam como biostásticos pela redução drástica deste elemento na forma disponível para microfiora da raiz (KLOEPPER et al., 1980). BUYER \& SIKORA (1990) fizeram revisões bibliográficas extensivas sobre os sideróforos e o possível papel desses compostos no biocontrole de fitopatógenos. BUYER \& LEONG (1986) estudaram a causa do antagonismo e efeito benéfico no crescimento de plantas de batata pelo isolado de Pseudomonas sp. fluorescente. Os autores concluíram tratar-se de "Pseudobactin", sideróforo produzido pela bactéria, o principal mecanismo que proporcionou esses efeitos.

YUEN et al., (1987) estudaram os papéis da competição por ferro e da antibiose pelo biovar IV de $\boldsymbol{P}$. fluorescens, na inibição de Pythium ultimum. Os autores observaram que mutantes não produtores de sideróforos também inibiam o patógeno, o mesmo não ocorrendo com mutantes não produtores de antibióticos. O tratamento de sementes de beterraba com o mutante não produtor de sideróforo reduziu a infecção em $50 \%$ quando comparado com o isolado original sugerindo que a antibiose é muito mais importante do que a competição por ferro na inibição do patógeno no solo.

Conforme FURUYA (1991), isolados de Pseudomonas glumae demonstraram diferentes atividades antibióticas contra $\boldsymbol{P}$. solanacearum dependendo do meio de cultura usado. Raízes de mudas de tomateiro tratadas com uma suspensão do antibiótico produzido por isolado de $\boldsymbol{P}$. glumae e com um isolado não produtor de antibiótico, mostraram supressão da doença em ambos os casos. Esses resultados sugerem que outros mecanismos, além da produção destas substâncias, estão envolvidos no controle. A capacidade bacteriocinogênica e a habilidade de inibição, em condições de laboratório, de $\boldsymbol{P}$. fluorescens BC8 à $\boldsymbol{P}$. solanacearum raça 3 foram estudadas por GALLARDO et al., (1989). Os resultados obtidos mostraram que a cepa BC8 inibia o patógeno, devido a ação de uma bacteriocina denominada Fluocina BC8.

\section{COLONIZAÇÃO E SOBREVIVÊNCIA DE Pseudomonas spp. FLUORESCENTES}

No biocontrole de fitopatógenos de rizosfera é extremamente importante o estabelecimento e a manutenção de populações dos antagonistas em níveis adequados (ROBBS, 1991). Segundo WELLER (1988), vários insucessos têm sido registrados com o emprego de antagonistas no biocontrole e entre as causas, destacam-se: (a) perda de competência ecológica e ocorrência de mutações envolvendo mudanças a estrutura da célula bacteriana e redução na produção de antibióticos, bacteriocinas e sideróforos; (b) ausência do patógeno-alvo, com a interferência de outros microrganismos secundários e não alvos; c) colonização irregular do rizoplano. Toma-se, portanto, importante o estabelecimento de adequada colonização do rizoplano, não só em todas as raízes do hospedeiro, bem como, ao longo destas (ROBBS, 1991). A migração rápida e ocupação de novas raízes em crescimento são ainda fatores importantes no estabelecimento e introdução de microrganismos na rizosfera (BOWEN \& ROVIRA, 1976), proporcionando uma competitiva vantagem para colonização e biocontrole (SUSLOW \& SCHROTH, 1982).

O uso de mutantes resistentes aos antibióticos rifampicina e ácido nalidixico tem sido uma importante erramenta para estudos de sobrevivência, crescimento e amplitude de Pseudomonas biocontroladoras, Ciência Rural, v. 27, n. 1, 1997. 
no solo e em plantas (ROVIRA et al, 1992). Para determinação qualitativa e quantitativa de populações bacterianas sobre raízes, pode-se usar microscópio óptico ou eletrônico. $\mathrm{O}$ uso da microscopia eletrônica adiciona uma nova dimensão aos estudos das associações bactéria-raízes e geralmente complementa dados obtidos por outros estudos (ROVIRA \& CAMPBELL, 1975).

A capacidade de colonização de raízes por bactérias em solo arenoso foi verificada por SCHER et al, (1 984). Dos 54 isolados testados, 24 foram capazes de competir com os microrganismos nativos do solo e colonizar raízes de milho. Dois isolados de Pseudonwnas fluorescentes não conseguiram colonizar solo natural, mas foram promissores em solos esterilizados, indicando que a competição microbiana teve um efeito negativo na capacidade de colonização.

Ao estudarem a dinâmica populacional dosisolados B4 e B 1 O de $\boldsymbol{P}$. fluorescens e $\boldsymbol{P}$. putida, LOPER et al., (1985) observaram, em ambos os casos, correlação com a quantidade inicial de inoculo. No entanto, a um certo nível, a população de B4 foi consistentemente maior e mais estável do que a de $\mathrm{B} 1 \mathrm{O}$, demonstrando variabilidade entre isolados.

A colonização de raízes de feijoeiro por $\boldsymbol{P}$. putida está relacionada com a produção de formas adicionais e altos níveis de peroxidase, sobre a superfície das raízes, conforme relatado por ALBERT \& ANDERSON (1987). O aumento da atividade desta enzima nas raízes colonizadas por esta bactéria tem potencial para contribuir na resistência da planta e pode aumentar a habilidade direta de $\boldsymbol{P}$. putida em suprimir certos patógenos fúngicos.

$\boldsymbol{P}$. fluorescens BC8 antagónica à $\boldsymbol{P}$. solanacearum foi capaz de colonizar raízes de plântulas de batata, e uma vez estabelecida, impediu a entrada do patógeno (GALLARDO \& PANNO, 1989). A capacidade epifitica de mutantes de $\boldsymbol{P}$. viridiflava resistentes a rifampicina e lácido nalidíxico, em raízes e folhas de cultivares de tomate susceptível e resistente, bem como de 16 espécies de ervas daninhas, em condições de casa de vegetação e campo foi estudada por MARIANO \& McCARTER (1993). As populações variaram em diferentes anos, o que foi atribuído a diferentes condições de temperatura. Alguns hospedeiros se mostraram mais viáveis que outros em proporcionar o crescimento epifitico dos mutantes, enquanto que as raízes foram melhores sítios de sobrevivência do que a folhagem.

\section{EFEITO DE Pseudomonas spp. FLUORESCENTES NO CRESCIMENTO DE PLANTAS}

As bactérias que colonizam as raízes podem também incitar um aumento no desenvolvimento e na produção do hospedeiro (KLOEPPER $\boldsymbol{e t}$ al., 1980), sendo denominadas de rizobactérias promotoras de crescimento de plantas (RPCP). Cerca de 2 a $5 \%$ das bactérias isoladas do sistema radicular promovem uma resposta positiva no crescimento de plantas (SCHROTH \& HANCOCK, 1981). O tratamento de sementes ou raízes de plântulas com bactérias que irão induzir aumento de crescimento é denominado bacterização(BROWN, 1974).

Os métodos de inoculação podem afetar a distribuição e população de RPCP nas raízes, destacando-se os de irrigação e incorporação do inoculo ao solo, como os mais eficientes. Com relação a aplicação do inoculo em sementes seguindo-se o armazenamento ou plantio em solos secos, recomenda-se o revestimento destas com protetores contra dessecação (SCHROTH \& BECKER, 1990). Há registros na literatura dos possíveis mecanismos utilizados pelas RPCP para a produção do crescimento em plantas, destacando-se a elaboração de fitohormônios, eliminação e alteração da microfiora deletéria (MELO, 1987), seja por antibiose (YUEN, et al, 1987; LOPER, 1985) ou pela competição por nutrientes, destacando-se entre eles o ferro e o carbono (ELAD \& BAKER, 1985).

Os benefícios da bacterização de sementes e raízes incluem proteção contra patógenos de raiz, produção de substâncias biologicamente ativas (com auxinas e giberelinas), transformação de minerais inviáveis e compostos orgânicos em formas viáveis para as plantas e, ainda, possibilidade de fixação de nitrogénio (BROADBENT et al, 1977). Em casa de vegetação, a bacterização de batatas sementes com suspensão de dois isolados de pseudomonas fluorescentes obtidos da periderme de batata, causaram aumento de até $500 \%$ no crescimento de plantas. No campo, a colonização da rizosfera pelas bactérias benéficas resultou em aumentos de 25 a $550 \%$ no comprimento dos estolões, bem como de 12 a $17 \%$ na produção, em função do tipo de solo (KLOEPPER et al., 1980).

O potencial antagónico de três isolados de pseudomonas fluorescentes contra Streptomyces scabies, agente causal da sarna comum da batata, foi testado em condições de campo, acarretanmdo aumento de $17,17 \%$ no índice de emergência, pelo isolado C-21 de T*, marginalis (MARIANO et al, 1992). A aplicação de isolados de pseudomonas fluorescentes em sementes de trigo (Triticum sativum L.) em casa de vegetação e também no campo, resultou em aumento de $147 \%$ no crescimento das plantas, em solo fumigado e $27 \%$ em solo natural (WELLER \& COOK, 1983). Sementes de tomateiro bacterizadas com isolados de pseudomons fluorescentes tiveram aumentos de 
germinação de 93, 88, 87 e $85 \%$ causados, respectivamente, pêlos isolados RJ22,612, RJ11 e JAI (STEIN, 1988).

Foi testada a ação de oito isolados de pseudomonas fluorescentes sobre a emergência, o peso seco e a altura de plântulas de tomate, cultivar Santa Cruz-Kada, através da bacterização de substrato, semente e substrato + semente, observando-se que os isolados FR48 e TR33 destacaram-se no aumento de emergência com valores médios de respectivamente 33,0 e 31,9\%, enquanto que FR 44 e FR 48 proporcionaram maior aumento de peso seco, com valores médios de 48,0 e $45,4 \%$. FR 48 e FR 44 proporcionaram maior aumento de altura, com valores médios de, respectivamente, 19,6 e 17,4\%. O método de bacterização de substrato + semente com espécies de pseudomonas fluorescentes foi, de modo geral, o mais eficiente para a promoção de crescimento de plântulas de tomateiro (PEIXOTO, 1994).

Plantas de Eucatyptus citriodora L. cultivadas em substratos com isolados de Trichoderma spp. ou espécies de pseudomonas fluorescentes, juntamente com Cylindrocladium clavatum, agente causal do tombamento de mudas, tiveram a porcentagem de peso fresco da parte aérea $(92,4$ a $125,8 \%)$ superior a do tratamento inoculado apenas com o patógeno (65,3 a 81,9\%) (BLUM \& LIN, 1991). Plântulas de rabanete (Raphanus salivas L.) que tiveram sementes bacterizadas com diversos isolados de $\boldsymbol{P}$. fluorescens, $\boldsymbol{P}$. marginalis $\mathrm{e}$ B. subülis apresentaram aumentos de altura de até 28,5\%, mas não foi observado aumento da germinação (ASSIS et al, 1992).

\section{CONCLUSÃO}

Por ser Pseudomonas solanacearum um patógeno de controle bastante difícil, e por não possuir um produto químico eficiente e viável economicamente para reduzir a infecção em tomateiros, acredita-se que métodos alternativos de controle devem ser testados visando-se a redução do potencial de inoculo de $\boldsymbol{P}$. solanacearum, no solo.

A opção pelo controle biológico, através da introdução ou manejo de bactérias antagónicas, como as Pseudomonas do grupo fluorescente, nos locais de colonização do patógeno, é um processo económico que tem se mostrado bastante promissor, possivelmente, por estes antagonistas possuírem eficientes mecanismos de ação; por serem capazes de promover o crescimento de plântulas, bem como apresentarem excelente sobrevivência e colonização na rizosfera/rizoplano de plantas. Constitui-se, portanto, numa estratégia atrativa para o controle da Murcha Bacteriana proporcionando proteção biológica contra a infecção podendo tomar o solo supressivo. Entretanto, para obter-se estes resultados satisfatórios, há a necessidade que a população antagónica introduzida mantenha-se estável no solo, necessitando um certo período de tempo para se estabelecer, tomando-se, portanto, um método de controle lento, se aplicado como alternativa única. No entanto, apresenta a vantagem de poder interagir com outros métodos de controle como o uso de variedades resistentes e a rotação de culturas, sendo, então, uma alternativa eficiente de controle integrado, e uma opção viável aos agricultores de baixa renda, além de causar menor impacto.

\section{REFERENCIAS BIBLIOGRÁFICAS}

ALBERT, F., ANDERSON, A. The effeet of Pseudomonas putída colonization on root surface peroxidase. Plant Physiology, Rockville, v. 85, p. 537-541, 1987.

ANARUTHA, C.S., GNANAMAN1CKAM, S.S. Biological control of bacterial wilt caused by Pseudomonas solanacearum $m$ índia with antagonistic bactéria. Plant and Soil, Dordreehet, v. 124, p, 109-116,1990.

ASSIS, S.M.P., MARIANO, R.L.R., SOUZA, E.B., et al. Efeito da bacterização de sementes na germinação e desenvolvimento de plântulas de rabanete. In: SIMPÓSIO DE CONTROLE BIOLÓGICO, 3. Anais... Jaguariúna: EMBRAPA-CNPDA, 1992.p.281.

BLUM, L.E.B., LIN, M.T. Potencial de Trichoderma e Pseudomonas fluorescentes para o controle de mudas de eucalipto causado por Cylindrocladium spp. Fitopatologia Brasileira, Brasília, v. 16, n. 1, p. 71-74, 1991.

BOWEN, G.D., ROVIRA, A.D. Microbiological colonization of plants roots. Annual Review of Phytopatology, Paio Alto, v. 14,p.121-144, 1976.

BROWN, M.E. Seed and root baeterizacion. Annual Review of Phytopatology, Paio Alto, v. 12, n. 2, p. 181-197, 1974.

BROADBENT, P., BAK.ER, K.F., FRANKS, N. et al. Efíeet of Bacilius spp. on increased growth ofseediing in steamed and in nontreated soil. Phytopatology. St. Paul, v. 67, n. 8, p. 1027-1034, 1977.

Leonardo Maciel Andrade, BUDDENHAGEN, I., KELMAN, A. Biological and physiological aspects of bacterial wilt caused by Pseudomonas sotonacearum Annual Review of Phytopatology, Paio Alto, v. 2, p. 203-230, 1964.

BUYER, J.S., LEONG, J. Iron transport - mediated antagonism between plant growth - promoting and plant - deleteriais Pseudomonas strains. The Journal of Biological Chemistry, Bethesda, v. 261, n. 2, p. 791-794, 1986. 
BUYER, J.S., SIKORA, L.J. Rhizosphere interacions and siderophores. Plant and Soil, Dordrechet, v. 129, p. 101-107, 1990.

CIAMPI-PANNO, L., FERNANDEZ, C., BUSTAMANTE, P., $\boldsymbol{e}$ al. Biológica! control of bacterial wilt of potatoes caused by Pseudomonas solanacearum American Potato Journal, Oronto, v. 66, p. 315-332, 1989.

ELAD, Y., BAKER, R. The role ofeompetition for iron and carbon in supression ofchamydospore gennination ofFusariumspp. Phytopatology, St. Paul, v. 75, n. 9, p. 1053 1059, 1985.

FUTUYA, N., KUSHIMA, Y., TSUCHIYA, K. et al. Protection of tomato seediing by pre-treatment with Pseudomonas gliimae from infection with Pseudomonas solanacearum and its mechanisms. Annals of the Phytopathological Society of Japan, Tokyo, v. 57, n. 3, p. 363-370, 1991.

GALLARDO, P.B., PANNO, L.C. Control biológico de Ia marchitez bacteriana de Ia papa (Solanum tuberosum L.) inducida por Pseudomonas solanacearum E.F. Smith. Revista de Microbiologia, São Paulo, v. 20, n. 1, p. 18-26, 1989.

GALLARDO, P.B., PANNO, L.C., GUICHAQUELÉN, V.G. Inibicion in vitro de Pseudomonas fluorescentes. Revista de Microbiologia, São Paulo, v. 20, n. 1, p. 27-33,1989.

GRANADA, G.A., SEQUEIRA, L. Survival of Pseudomonas solanacearum $m$ soil, rhizosphere, and, plant roots. Canadian Journal oTMicrobiology, Ottawa, v. 29, p. 433 $440,1983$.

HARTMAN, G.L., HONG, W.F., HANUDIN et al. Potencial of biological and chemical control of bacterial wilt. In: HARTMAN, G.L. \& HAYWARD, A.C. (Eds.). Bacterial wilt. Canberra: ACIAR Proceeding, 1993. p. 322-326.

HAYWARD, A.C. Bacterial wilt by Pseudomonas solanacearum in Ásia and Austrália: an overview. In Bacterial wilt Disease in Ásia and South Pacifc. AC1AR, 1986. p. $25-26$

HAYWARD, A.C. Characteristes of Pseudomonas solonacearum. Journal of AppIied Bacteriology, London, v. 27 , n. 2, p. $265-277,1964$.

HORNBY, D. Take-all decline: a theorisfs paradise. In: SCHIPPERS, B. \& GAMS, W. (Eds.). Soil-borne plant pathogens, London: Academic Press, 1979, p. 271-293.

HOWELL, C.R., STIPANOVIC, R.D. Control of Rhizoctonia solam on cotton seediings with Pseudomonas fluorescens and with an antibiotic produced by the bacterium. Phytopatology, St. Paul, v. 69, n. 5, p. 480-482, 1979.

KELMAN, A. Mission ofthe conference. In: SEQUEIRA, L. \& KELMAN, A. (Eds.). Proceedings of the first international planning conferencee and workshop on the ecology and control of bacterial wilt caused by Pseudomonas solanacearum. Releigh: North Carolina State University, 1976, p. 1-5.

KELMAN, A. The relationship ofpathogenicity in Pseudomonas solanacearum to colony appearance on a tetrazolium médium. Phytopatology, St. Paul, v. 44, n. 12, p. 693-695, 1954.

KLOEPPER, J.W., SCHROTH, M.N., MILLER, T.D. Effects of rhizosphere colonization by plant growth-promoting rhizobacteria on potato plant development and yield. Phytopatology, St. Paul, v. 70, n. 11, p. 1078-1082, 1980.

LIÃO, C.H. Antagonism of Pseudomonas putída strain PP22 to phytopatogenic bactéria and its potential use as a biocontrol agent. Plant Disease, St. Paul. v. 73, n. 3, p. 223-226,1989.

LOPER, J.E., HAACK, C., SCHROTH, M.N. Population dynamics of soil pseudomonads in the rhizosphere of potato (Solanum tuberosum L.). Appiied and Environmental Microbiology, Washington, v. 49, n. 2, p. 416-422,1985.

MALA VOLTA JR., V.A., RODRIGUES NETO, J. Controle de doenças causadas por bactérias em tomateiro. In: CATELLANE, P.D., BRA2, L.T., CHURATA-MASCA, M.G.C. (Coords.). ENCONTRO NACIONAL DE PRODUÇÃO E ABASTECIMENTO DE TOMATE, 2, Anais..., Jaboticabal: ED. UNESP, 1991, p. 165.

MAR1ANO, R.L.R., BARROS, S.T., MENEZES, D., et al. Potencial antagónico de Trichoderma spp. e Pseudomonas spp. fluorescentes contra Streptomyces scabies, agente causal da sarna comum da batata. In: SIMPÓSIO DE CONTROLE BIOLÓGICO, 3. Anais... Jaguariúna: EMBRAPA-CNPDA 1992.p. 280.

MARIANO, R.L.R., McCARTER, S.M. Epiphytic survival of Pseudomonas viridiflava on tomato and selected weed species. Microbial Ecology, New york, v. 26, n. 1, p. 47-58, 1993.

MARIANO, R.L.R., MICHEREFF, S.J., HOLANDA, V.T. et al. Controle biológico de Pseudomonas solanacearum em tomateiro com Pseudomonas spp. fluorescentes. In: Congresso Paulista de Fitopatologia. Jaguariúna: Grupo Paulista de Fitopatologia, 1989, p. 218.

MARTINS, O.M., TAKATSU, A., REIFSCHNEIDER, F.J.B Virulência de biovares I e II de Pseudomonas solanacearum ao tomateiro. Fitopatologia Brasileira, Brasília, v. 13, n. 3, p. $249-252,1988$

McCORMACK, R.B. Algumas observações sobre as moléstias das plantas em Pernambuco. Boletim da Secretaria de Agricultura Industria e Comércio do Estado de Pernambuco, Recife, v. 2, n. 1, p. 90-104, abril 1937.

McLAUGHLIN, R., SEQUEIRA, L. Evaluation ofavirulent strain of Pseudomonas solanacearum for biological control of bactéria! wilt of potato. American Potato Journal, Oronto, v. 65 , n. 5, p. $255-268,1988$.

MELO, 1.S. de. Efeitos de rizobactérias no desenvolvimento de plantas. In: REUNIÃO SOBRE CONTROLE BIOLÓGICO DE DOENÇAS DE PLANTAS, 2. Anais... Campinas: Fundação Cargil, 1987, p. 16-19.

MEW, T.W., HO, W.C. Varietal resistence to bacterial wilt in tomato. Plant Disease Repórter, Beltsville, v. 60, n. 3, p. 264-268,1976.

MOFFETT, M.L., GILES, J.E., WOOD, B.A. Survival of Pseudomonas solanacearum biovars 2 and 3 in soil: effect of moisture and soil type. Soil Biol. Biochem, Oxford, v. 15, n. 5, p.587-591, 1981

PEIXOTO, A.R., Açio antagónica de Pseudomonas spp. fluorescentes contra $P$. solanacearum (Smith) Smith, 
agente causal da Murcha Bacteriana do tomateiro (Lycopersicon esculentum Mill). Recife, 1994, 149 p. Dissertação (Mestrado em Fitossanidade) Universidade Federal Rural de Pernambuco.

PERSLEY, G.L..-BATUGAL, P., GAPASIA, D., et al. Summary ofdiscussion and recommendations. In: PERSLEY, G.L. (Ed.). Bacterial wilt disease in Ásia and South Pacifc: ACIAR, 1986.p.7-14.

RAO, M.V.B, SOH1, H.S., TIKOO, S.K. Reaction ofwilt resistant tomato varieties and lines to Pseudomonas solanacearum $m$ índia. Plant Disease Repórter, Beltsville, v. 59 , p. $734-736,1975$.

REIFSCHNE1DER, F.J.B., TAKATSU, A. Pseudomonas solanacearum no Brasil: Aspectos macroepidemiológicos. Fitopatologia Brasileira, Brasília, v. 10, n. 2 p. 213, 1985.

RIBEIRO, Z.M. de A.A., TAKATSU, A. Avaliação de rizobactérias isoladas de plantas invasoras para controle de murcha bacteriana em tomateiro. Fitopatologia Brasileira, Brasília, v. 18, Suplemento, p. 313, 1993.

ROBBS, C.F. Bactérias como agentes de controle biológico de fitopatógenos. In: BETTIOL, W. (Ed.). Controle biológico de plantas. Jaguariúna: EMBRAPA-CNPDA, 1991. p. 121133.

ROVIRA, A.D., CAMPBELL, R. A scanning electron microscope study of interactions between microorganisms and Gaeumannomyces graminis on wheat roots. Microbial Ecology, Ney York, v. 2, p. 177-195, 1975.

ROVIRA, A., RYDER, M., HARRIS, A. Biological control ofroot diseases with pseudomonads. In: IJAMOS, E.S. et al. (Eds.). Biological control of lant diseases. New York: Plenum Press, 1992.p.175-184.

SCHER, F.M., ZIEGLE, I.S., KLOEPPER, J.W. A method for assessing the root-colonizing capacity of bactéria on maize. Canadian Journal of Microbiology, Ottawa, v. 30, n. 1, p. $151-157,1984$

SCHROTH, M.N., BECKER, J.O. Concepts of eeological and physiological activities of rhizobacteria related to biologic control and plant growth promotion. In: HORNBY, D. (Ed.). Biológical control of soil-borne plant pathogens. Wailingford: C.A.B. Internacional, p. 389-414, 1990.
SCHROTH, M.N., HANCOCK, J.G. Selected topics in biological control. Annual Review of Microbiology, Paio Alto, v. 35, p. $453-476,1981$.

SIMON, A., RYDER, M., HARRIS, A. Biological control of soil borne root diseases for increased plant production. Glen Osmond: CSIRO Division ofsoils, 2 p., 1990.

SINHA, S.K. Bacterial wilt in índia. In: PERSLEY, G.L. (Ed.). Bacterial Wilt Disease in índia and the South Pacific. ACIAR, 1986. p. 28-29.

STEIN, R.L.B. Efeito de Pseudomonas spp. fluorescentes no controle in vitro de fungos do solo e no desenvolvimento do tomateiro (Lycopersicon esculentum Mill). Recife, 1988, 125 p. Dissertação (Mestrado em Fitossanidade) Universidade Federal Rural de Pernambuco.

SUSLOW, T.V., SCHROTH, M.N. Rhizobacteria of sugar beets: effects of seed appiication and root colonization on yield. Phytopatology, St. Paul, v. 72, n. 2, p. 199-206, 1982.

WALL, G.C., SANCHEZ, J.L. A biocontrol agent for Pseudomonas solanacearum. In: HATMAN, G.L. \& HAYWARD, A.C. (Eds). Bacterial wilt. ACIAR Proceding, 1993. p. $320-321$.

WALLIS, F.M., TRUTER, S.J. Histopathology of tomato plants infected wilt Pseudomonas solanacearum, with emphasis on ultrastrueture. Physiological Plant Pathology, London, v. 13, n. 3, p.307-317, 1978.

WELLER, D.M. Biologieal control ofsoilbome plant pathogens in the rizosphere with bactéria. Annual Review of Phytopatology, Paio Alto, v. 26, p. 379-407, 1988.

WELLER, D.M., COOK, R.J. Suppression fo take-all of wheat by seed treatments with fluorescent pseudomonads. Phytopatology, St. Paul, v. 73, n. 3, p. 463-469, 1983.

YUEN, G., HENDSON, M., RELLA, M. et al. The roles ofiron competition and antibiosis in the inhibition of Pythium ultimum by Pseudomonas fluorescens biovar IV. Phytopatology, St. Paul. v. 17, n. 12, p. 1758, 1987.

Ciência Rural, v. 27, n. 1, 1997. 